Note

\section{5-AF2, a Cell Aggregation Factor Produced by Streptomyces sp. Strain No. A-3315}

\author{
Masaru UyedA, Keitarou SUZUKI \\ and Motoo Shibata \\ Laboratory of Medicinal Microbiology, Faculty of \\ Pharmaceutical Sciences, Kumamoto University, \\ Kumamoto 862, Japan
}

Received August 31, 1989

Some cell aggregation substances produced by microorganisms do not aggregate human erythrocytes, but do aggregate microorganisms and animal cells differentially. ${ }^{1-3)}$

We have previously reported that Serratia aggregation factor (SAF), produced by Steptomyces murinus strain No. A-2805, is a glycoprotein and that the factor was able to aggregate some bacterial cells, and sarcoma 180 and HeLa cells in the presence of calcium or manganese ions. ${ }^{4-5)}$ Recently, we found that Streptomyces sp. stain No. A3315 produced two kinds of aggregation factors, designated as 3315-AF and 3315-AF2, in the culture filtrate. 3315-AF was purified and some of its properties were described in the previous paper. ${ }^{6)}$ We now report the purification of $3315-\mathrm{AF} 2$ and some differences between SAF and 3315-AF.

The aggregation activity toward bacterial cells was measured as the degree of the decrease in the turbidity of a cell suspension. One unit of aggregation activity was defined as the amount of factor causing a decrease in the optical density at $660 \mathrm{~nm}$ of 0.2 per $120 \mathrm{~min}$. The reaction mixture and conditions were described in our previous paper. $^{4)}$

Streptomyces sp. strain No. A-3315 was cultivated for 14 days under the same conditions as described in the preceding paper ${ }^{6)}$ and the mycelia were removed by centrifugation. To the culture filtrate was added active carbon powder, followed by stirring $30 \mathrm{~min}$. After the carbon had been removed by filtration, an equal volume of cold ethanol was added to the filtrate. The precipitate was dispersed in deionized water, and applied on a Sepharose $2 \mathrm{~B}$ column and eluted with a $\mathrm{NH}_{4} \mathrm{OH}$ solution $(\mathrm{pH} 8)$. The active fraction was extracted with ether at $\mathrm{pH} \mathrm{4,} \mathrm{and} \mathrm{then}$ the extract was applied on a silica gel column and eluted with the solvent pair of $n$-hexane and ether. The active fractions (crude solution) containing 3315-AF and 3315AF2 were combined, and then the solution was applied on a Sephadex LH-20 column equilibrated with 2-propanol. Two peaks of aggregation activity appeared, the first fraction being $3315-\mathrm{AF}$, which was reported in the previous paper. ${ }^{6)}$ To obtain $3315-\mathrm{AF} 2$, the fractions comprising the second peak were combined, and then silica gel column chromatography and gel filtration on Sephadex LH-20 were repeated under the respective conditions. 3315 -AF 2 was purified about 21 -fold on the basis of the OD at $275 \mathrm{~nm}$, with a yield of $1.3 \%$ from the crude solution. Finally, we obtained about $1.4 \mathrm{mg}$ of $3315-\mathrm{AF} 2$ from one liter of culture filtrate, the aggregation activity of the factor toward Serratia being 68 units per mg.

3315-AF2 was a colorless and oily liquid. It was soluble in ethanol, 2-propanol and $n$-hexane, but insoluble in water. It showed a positive $\mathrm{H}_{2} \mathrm{SO}_{4}$ reaction, and negative Dittmer, ninhydrin, $\mathrm{FeCl}_{3}$ and $\mathrm{SbCl}_{3}$ reactions on TLC. 3315 -AF2 gave a single spot, $R f 0.49$, with $n$-hexane-ether (4:1) on TLC on a Merck Silica gel $60 \mathrm{~F}_{254}$ plate, 0.89 with 2-propanol-acetonitrile (1:1) on a Merck RP-8F 254 plate and 0.94 with benzene-ether $(4: 1)$ on a silica gel (type $\mathrm{G}$ ) containing $20 \% \mathrm{AgNO}_{3}$ plate. The $\mathrm{UV}$ spectrum in 2-propanol showed a maximum at $275 \mathrm{~nm}$ ( $E$ value, 34.4 ), and the IR spectrum showed peaks at 2964, 2936, 2868, 1734, 1124 and $1074 \mathrm{~cm}^{-1}$. The ${ }^{1} \mathrm{H}$ and ${ }^{13} \mathrm{C}$ NMR signals are shown in Table I. From these results, the structure of 3315-AF2 was determined to be bis(2ethylhexyl) phthalate. Garner and Watson") reported that this compound was obtained from a reaction mixture of 2 octanol, phthalic anhydride and xylene by means of steam distillation. However, it is interesting that this compound was obtained from the culture filtrate of a streptomycetes strain.

In Table II, some properties of $3315-\mathrm{AF} 2$ are sum-

Table I. NMR DATA FOR 3315-AF2

\begin{tabular}{ccl} 
Position & ${ }^{13}$ C NMR & ${ }^{1} \mathrm{H}$ NMR \\
\hline 1 & $11.0^{*}(\mathrm{q})$ & $0.90^{*}(\mathrm{t})$ \\
2 & $23.0(\mathrm{t})$ & $1.26-1.48$ \\
3 & $23.8(\mathrm{t})$ & $1.26-1.48$ \\
4 & $29.0(\mathrm{t})$ & $1.26-1.48$ \\
5 & $38.8(\mathrm{~d})$ & $1.56-1.72$ \\
6 & $68.2(\mathrm{t})$ & $4.22(\mathrm{~m})$ \\
7 & $167.8(\mathrm{~s})$ & \\
8 & $14.1(\mathrm{q})$ & $0.92(\mathrm{t})$ \\
9 & $30.4(\mathrm{t})$ & $1.26-1.48$ \\
10 & $132.5(\mathrm{~s})$ & \\
11 & $130.9(\mathrm{~d})$ & $7.69(\mathrm{~m})$ \\
12 & $128.8(\mathrm{~d})$ & $7.54(\mathrm{~m})$ \\
\hline
\end{tabular}

* ppm

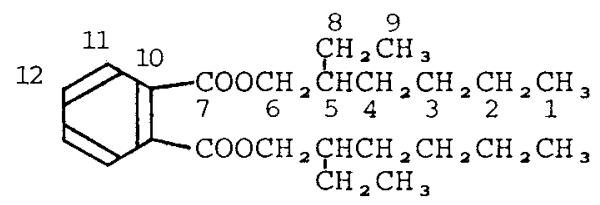

3315-AF2, bis(2-ethylhexyl) phthalate. 
Table II. COMPARISON OF 3315-AF2 WITH 3315-AF AND SAF

\begin{tabular}{|c|c|c|c|}
\hline & 3315-AF2 & 3315-AF & SAF \\
\hline Producer & Streptomyces $\mathrm{sp}$. & No. A-3315 & St. murinus No. A-2805 \\
\hline Localization & Extracellular & Extracellular & Intracellular \\
\hline Structure & Phthalate & Triglyceride & Glycoprotein \\
\hline Activity (unit/mg) & 68.0 & 76.0 & 15.0 \\
\hline Optimum $\mathrm{pH}$ & 7.0 & 8.0 & 8.0 \\
\hline Optimum temp. $\left({ }^{\circ} \mathrm{C}\right)$ & 28.0 & 27.0 & 30.0 \\
\hline Activator & $\mathrm{Ca}, \mathrm{Co}, \mathrm{Ba}$ & $\mathrm{Ca}, \mathrm{Co}, \mathrm{Ba}$ & $\mathrm{Ca}, \mathrm{Mn}$ (essential) \\
\hline \multicolumn{4}{|l|}{ Inhibitor; $\mathrm{ID}_{50}(\mu \mathrm{g})$} \\
\hline BSA & 5 & 24 & 26 \\
\hline Hyaluronic acid & 13 & 24 & $>100$ \\
\hline Laminarin & $>100$ & $>100$ & 56 \\
\hline \multirow[t]{4}{*}{ Aggregation } & S. marcescens, & P. vulgaris & S. marcescens \\
\hline & S. cerevisiae, & C. albicans & $E$. coli, $M$. luteus \\
\hline & C. neoformans, & HeLa & B. subtilis, $S$. aureus \\
\hline & & & HeLa, Sarcoma 180 \\
\hline
\end{tabular}

marized, and compared with those of 3315-AF and SAF. 3315-AF2 is similar to $3315-\mathrm{AF}$ in its properties, but is distinguishable from SAF. The activity of 3315-AF2 turned out to be $\mathrm{pH}$ - and temperature-dependent, the optimum $\mathrm{pH}$ and temperature being 7.0 and $28^{\circ} \mathrm{C}$, respectively. 3315-AF2 and 3315-AF aggregated Serratia in the absence of metallic ions, and the activity was enhanced by the addition of $\mathrm{CaCl}_{2}, \mathrm{CoCl}_{2}$ and $\mathrm{BaCl}_{2}$. On the other hand, SAF required metallic ions for aggregation. The aggregation activities of 3315-AF2 and 3315-AF were not inhibited by mono- or disaccharides, but both factors were inhibited by hyaluronic acid and bovine serum albumin. The degree of this inhibition against $3315-\mathrm{AF} 2$ was stronger than that against 3315-AF. 3315-AF2 aggregated Proteus vulgaris and HeLa cells as well as Serratia marcescens, and showed weak activity toward Saccharomyces cerevisiae, Candida albicans and Cryptococcus neoformans, but could not aggregate Pseudomonas aeruginosa, Staphylococcus aureus, Micrococcus luteus, Bacillus subtilis or the animal cells such as human erythrocytes (A, B, O and AB-type), leukemia P388 cells, lymphocytes, macrophages, sarcoma 180 cells or hepatoma AH109A cells (data not shown).

3315-AF2 turned out to be a kind of phthalate derivative and is thought to undergo some interaction with the hydrophobic sites on the cell membranes from its lipophilic nature.

\section{References}

1) K. Oishi and K. Aida, Agric. Biol. Chem., 39, 183 (1975).

2) T. Ikekawa, T. Asari, T. Manabe, M. Umeji, S. Yanoma and K. Oishi, J. Antibiot., 33, 776 (1980).

3) K. Sakka, T. Endo, M. Watanabe, S. Okuda and H. Takahashi, Agric. Biol. Chem., 46, 497 (1981).

4) K. Suzuki, M. Kosai, M. Uyeda and M. Shibata, Agric. Biol. Chem., 51, 3017 (1987).

5) K. Suzuki, M. Kosai, K. Yokomizo, M. Uyeda and M. Shibata, Agric. Biol. Chem., 52, 555 (1988).

6) K. Suzuki, N. Nakano, R. Tanaka, M. Uyeda and M. Shibata, Agric. Biol. Chem., 52, 2589 (1988).

7) P. J. Garner and G. Watson, U.S. Patent 2,508,911 (May 23, 1950). 